Macedonian Pharmaceutical Bulletin, 66 (Suppl 1) 151 - 152 (2020)

Online ISSN 1857 - 8969

UDC: $615.357 .37-07$

DOI: 10.33320/maced.pharm.bull.2020.66.03.075

Short communication

\title{
Quality study of insulin formulations
}

\author{
Blerta Pajaziti ${ }^{1}$, Attila Gaspar ${ }^{2}$, Melinda Andrási $^{2}$, Dashnor Nebija $^{3}$, \\ Rumenka Petkovska ${ }^{1}$ *
}
${ }^{I}$ Faculty of Pharmacy, Ss. Cyril and Methodius University, Mother Theresa 47, 1000 Skopje, North Macedonia,
${ }^{2}$ Department of Inorganic and Analytical Chemistry, University of Debrecen, Egyetem tér. 1, 4032 Debrecen, Hungary
${ }^{3}$ Department of Pharmacy, University of Prishtina "Hasan Prishtina, Bulevardi i Dëshmorëve, p.n., 10000 Prishtina, Kosovo

\section{Introduction}

Diabetes mellitus is one of the most common metabolic diseases in the world. It is caused by an absolute or relative lack of insulin activity, leading to hyperglycemia. The most common treatment of hyperglycemia caused by Type 1 and 2 Diabetes mellitus is human insulin produced by recombinant DNA techniques which is structurally identical to endogenously produced human insulin. (Waller et al., 2005). In addition, a number of insulin analogs produced by modifying the structure of human insulin with the aim to change the rates of absorption and duration and time to action are available.

Currently two type of insulin analogues are available, rapid acting analogs (insulin lispro, insulin aspart and insulin glulisin) and long acting analogs: (insulin detemir, insulin glargine and insulin degludec) ( www.ema.europa.eu). Despite conventional vial and syringes methods, insulin formulations currently are administered using different prefilled insulin pen devices and also continuously using an insulin pump (Peters et al., 2016).

Orthogonal analytical methodologies including spectroscopy, chromatography, thermal analysis, electrophoresis, immunoassays, and bioassays are required to completely characterize biological medicines and examine their degradation profiles (Banga, 2006).

According European Pharmacopoeia, HPLC and peptide mapping are used for the evaluation of identity of human insulin and its analogs, whereas size exclusion chromatography (SEC) is used to test impurities with molecular masses greater than insulin/insulin analogs. In addition, RP-HPLC is used for the assessment of related substances and for the quantitative determination of active ingredient (European Pharmacopoeia, 2020).

Capillary electrophoresis (CE) has been established as a suitable technique for the quality study of biological drugs. This technique offers numerous advantages, including simplicity, high speed, excellent resolving power, sensitivity, low sample size requirements, low solvent consumption and ease of automation (Voeten et al., 2018).

The principal aim of this study was to develop a simple and fast CZE (capillary zone electrophoresis) /CGE (capillary gel electrophoresis) technique for the quality study of recombinant human insulin and its analogs, in regard to identification and the assessment of their purity and structural integrity.

\footnotetext{
* rupe@ff.ukim.edu.mk
} 


\section{Materials and methods}

CZE method

For CZE separations between each injection, the capillary was preconditioned for $5 \mathrm{~min}$ with the running buffer and post conditioned with $70 \mathrm{mM}$ SDS for $3 \mathrm{~min}, 1 \mathrm{M} \mathrm{NaOH}$ for $5 \mathrm{~min}$ and the buffer electrolyte for 4 min to remove all possible adsorbed materials. The buffer used was $50 \mathrm{mM}$ ammonium acetate $\mathrm{pH}$ 9. The samples were introduced at the cathodic end of the capillary; injections were performed using -50 mbar pressure for $4 \mathrm{~s}$.

\section{CGE method}

For CGE separations the precondition procedure was $1 \mathrm{M} \mathrm{NaOH}$ for $10 \mathrm{~min}, 1 \mathrm{M} \mathrm{HCl}$ for $7 \mathrm{~min}$ and the sieving matrix for $25 \mathrm{~min}$. The buffer used was a commercially available sieving matrix gel buffer (SDS-MW) by Beckman Coulter. The samples introduced using $+7.5 \mathrm{kV}$ for $50 \mathrm{~s}$.

\section{Results and discussion}

Experimental data showed that CZE was able to separate charge variants of insulin and its analogues. Capillary electrophoresis method resulted in the efficient separation of insulin/insulin analogs and their main impurities in less than 2 minutes, which is the obvious advantage in comparison to RP-HPLC method which currently is an official pharmacopoeia method.

CGE was used to separate the higher molecular weight transformation products. These products are unable to be separated by CZE, because in the case of dimer and other polymeric complexes of insulin, the $\mathrm{m} / \mathrm{z}$ ratio is still the same as the monomer of insulin. CGE is able to separate components depending on their mass.

\section{Conclusion}

In the present study the suitability of CZE and CGE method could be successfully demonstrated for the assessment of quality of pharmaceutical formulations containing human insulin and its analogs.

\section{Acknowledgements}

The research was supported by The National Research, Development and Innovation Office, Hungary (K127931).

\section{References}

Banga, A., 2006. Therapeutic peptides and proteins: Formulation, processing and delivery systems, second ed. CRC Press Taylor and Francis Group, Boca Raton, FL, pp.11-28.

Europan Medicines Agency, available at: www.ema.europa.eu.

European Pharmacopoeia 10th Edition, 2020, Strasbourg, France.

Peters, A.L., Ahmann, A.J., Battelino, T., Evert, A., Hirsch, I.B., Murad, M.B., Winter, W.E., Wolpert, H., 2016. Diabetes technology Continuous subcutaneous insulin infusion therapy and continuous glucose monitoring in adults: An Endocrine Society Clinical Practice Guideline. J. Clin. Endocrinol. Metab. 101(11), 3922-3937.

Voeten, R.L.C., Ventouri I.K., Haselberg R., Somsen G.W., 2018. Capillary electrophoresis. trends and recent advances. Anal. Chem. 90, 1464-1481.

Waller, D.G., Renwick, A.G., Hillier, K., 2005. Medical pharmacology and therapeutics, second ed. Elsevier Saunders, New York, pp. 125-137. 